\title{
Study of the cuttings transport in stable foam drilling
}

\author{
Jie Zhang ${ }^{1, *}$, Wen Luo ${ }^{1}$, Cuinan $\mathrm{Li}^{2}$, Tingyu Wan ${ }^{3}$, Zhen Zhang ${ }^{4}$, and Chenghua Zhou ${ }^{4}$ \\ ${ }^{1}$ State Key Laboratory of Oil and Gas Reservoir Geology and Exploitation, Southwest Petroleum University (SWPU), \\ Chengdu, Sichuan, China \\ ${ }^{2}$ Engineering and Technology Research Institute of Southwest Branch, PetroChina, Guanghan, Sichuan, China \\ ${ }^{3}$ Northwestern Sichuan Gas District of Southwest Branch, PetroChina, Jiangyou, Sichuan, China \\ ${ }^{4}$ Drilling Engineering Research Institute (DERI) of Southwest Branch, Sinopec, Deyang, Sichuan, China
}

Received: 17 June 2018 / Accepted: 19 July 2018

\begin{abstract}
Based on the special rheological model of foam fluid, the mathematical models of cuttings transport for stable foam drilling in vertical/near vertical sections, the transitional section, and inclined/horizontal sections are established in this paper. The effects of various flow parameters on the cuttings bed thickness in the annulus are analyzed. The results show that inclination, annulus velocity, foam flow rate, and eccentricity are key factors affecting cuttings transport. The thickness of a cuttings bed gradually decreases with the inclination decrease of the highly deviated/horizontal sections. When the inclination is reduced to approximately $60^{\circ}$, the dynamic and static cuttings bed disappears and is substituted by the glide lamella, which consists of cuttings grains. Cuttings grains have various forms of movement on the lower borehole wall. When the inclination is reduced to below $30^{\circ}$, the cuttings are brought out of the well by the stable foam if the returning velocity of the annulus foam is larger than the depositing velocity of the cuttings. The thickness of the cuttings bed gradually decreases with the increase of annulus velocity. The increased foam quality reduces the concentration of annulus cuttings when the annulus velocity is constant and when it reaches a stable status earlier than the foam drilling fluid of lower foam quality. However, the concentration of the annulus cuttings at the final stage is constant. The thickness of the cuttings bed increases with increased eccentricity of the drill stem. When the eccentricity is large, the change of eccentricity has a high effect on the cuttings bed thickness.
\end{abstract}

\section{Nomenclature}

$F_{\mathrm{D}} \quad$ Drag force, $\mathrm{N}$

$F_{\mathrm{L}} \quad$ The uplift force, $\mathrm{N}$

$F_{\mathrm{B}} \quad$ The buoyancy force, $\mathrm{N}$

$\theta \quad$ Well angle, ${ }^{\circ}$

$\Delta P \quad$ Pressure drop, $\mathrm{N}$

$\Delta L \quad$ Step size, $\mathrm{m}$

$v_{\mathrm{f}} \quad$ The velocities of the suspension layer, $\mathrm{m} / \mathrm{s}$

$v_{\mathrm{c}} \quad$ The velocities of the bed load cuttings, $\mathrm{m} / \mathrm{s}$

$\mathrm{v}_{s} \quad$ The velocities of the component of $v_{f}$ on the gravity direction, $\mathrm{m} / \mathrm{s}$

$v_{\mathrm{t}} \quad$ The mean velocities of mixtures in the annuli, $\mathrm{m} / \mathrm{s}$

$A_{\text {a }} \quad$ The cross sectional area of annuli

$A_{\mathrm{s}} \quad$ The sectional areas of the suspension layer

$A_{\mathrm{c}} \quad$ The sectional areas of the bed load

$A_{\mathrm{b}} \quad$ The sectional areas of the newly formed cuttings bed

\footnotetext{
* Corresponding author: swpivip@163.com
}

$A_{\mathrm{mb}} \quad$ The sectional areas of the dynamic cuttings bed

$A_{\mathrm{sb}} \quad$ The sectional areas of the static cuttings bed

$C_{\mathrm{s}} \quad$ The concentrations of cuttings in the suspension layer, \%

$C_{\mathrm{c}} \quad$ The concentrations of cuttings in the bed load, $\%$

$C_{\mathrm{b}} \quad$ The concentrations of cuttings in the newly formed cuttings bed, $\%$

$\tau_{\mathrm{s}} \quad$ The shearing forces between the suspension layer and the wall

$\tau_{\mathrm{smb}} \quad$ The shearing forces between the suspension layer and the bed load

$\tau_{\mathrm{mb}} \quad$ The shearing forces between the bed load and the wall

$\tau_{\mathrm{sb}} \quad$ The shearing forces between the static cuttings bed and the wall

$\tau_{\text {mbsb }} \quad$ The shearing forces between the static cuttings bed and the dynamic cuttings bed

$\tau_{s m b}^{\prime} \quad$ The shearing forces between the suspension layer and the dynamic cuttings bed 
$S_{\mathrm{s}} \quad$ The wetted perimeters between the suspension layer and the wall

$S_{\mathrm{smb}} \quad$ The wetted perimeters between the suspension layer and the bed load

$S_{\mathrm{mb}} \quad$ The wetted perimeters between the bed load and the wall

$S_{\mathrm{sb}} \quad$ The wetted perimeters between the static cuttings bed and the wall

$S_{\text {mbsb }}$ The wetted perimeters between the static cuttings bed and the dynamic cuttings bed

$\mathrm{S}_{\text {smb }}^{\prime}$ The wetted perimeters between the suspension layer and the dynamic cuttings bed

$\rho_{\mathrm{s}} \quad$ Densities of cuttings in the suspension layer

$\rho_{\mathrm{mb}} \quad$ Densities of cuttings in the bed load (dynamic cuttings bed)

$F_{\mathrm{mb}} \quad$ The sliding friction force between the suspension layer and the wall

$F_{\text {mbsb }}$ The sliding friction force between the static cuttings bed and the dynamic cuttings bed.

\section{Introduction}

With the extensive application of the directional or horizontal well in the exploration and development of oil and gas, researchers are paying increasingly more attention to the cuttings transport in inclined and horizontal boreholes. Tomren et al. (1983) studied the laws of cuttings transport in inclined tubes. They discovered that three forms of cuttings bed co-exist when cuttings move in inclined tubes: (a) static, (b) slip, and (c) suspension. Hagar et al. (1995) conducted a series of laboratory experiments to examine the mechanisms involved in solids transport in deviated wells. Ford et al. (1990) conducted an experimental investigation of drilled cuttings transport in inclined boreholes. Sample and Bourgoyne $(1977,1978)$ proposed a general method for calculating settling velocities from the polynomial fitting of multispeed rheograms, thus eliminating some of the uncertainties in the previous methods for designing cuttings transport in drilling. Gavignet and Sobey (1986) believed that cuttings exist in two forms: (a) the cuttings bed at the low side of the annulus and (b) the suspension layer covering it. Rooki et al. (2014) established the corresponding mathematical calculation model based on the mechanical analysis. Larsen et al. (1997) developed correlations from experimental data of cuttings transport in horizontal and high-angle wells. Masuda et al. (2000) presented data for laboratory experiments to determine the critical flow rate for cuttings transport in underbalanced drilling. Luo and Bern (1992) and Ford (1993) presented mathematical models for determining the minimum fluid velocity for transporting cuttings without the formation of a cuttings bed. Nguyen and Rahman (1998) established the three-layer flow mathematical model that is applicable to highly deviated and horizontal well sections. They also employed a computer for simulation calculation and discussed the laws of effect of different variables on cuttings bed thickness.
Furthermore, some empirical and mechanistic models have been developed for cuttings transport (Kelessidis and Bandelis, 2004; Piroozian et al., 2012). Kamp and Rivero (1999) corrected the original double-layer flow model, built a double-flow model that is applicable to the static flow of highly deviated well, and compared the simulation results of the model with experienced relational expression of cuttings transport. Through experiments, Kelessidis and Bandelis (2003) analyzed the annular flow and velocity of effective cuttings carriage during coiled tubing drilling of horizontal and directional wells and proposed a new method of calculating the minimum annulus velocity.

The current research on wellbore gas-liquid two-phase flow mainly focuses on the study of a single gas-liquid mixture. Thus, foam, a fluid that has a special rheological model, has not been considered. In addition, the research on cuttings carried by foam is limited to in terms of extending the application of the model universally. As a result, most models do not consider the difference between the movement mode of cuttings and the existing form of a cuttings bed in different sections. This paper establishes mathematical models of cuttings transport during stable foam drilling of vertical/near-vertical sections, a transition section, and inclined/horizontal sections to analyze the effect of inclination, the foam returning velocity, the foam flow rate, and the degree of eccentricity on cuttings transport. This study has important guiding significance for adjusting foam performance to improve the cleaning effect of cuttings in wells during drilling.

\section{Cuttings transport model of stable foam}

\subsection{Basic assumed conditions}

The assumed condition of cuttings transport for the mathematical model is provided below:

(1) the foam flow is at a stable rate, whereas gas-liquid phases do not have the phenomenon of slipping;

(2) the liquid phase of foam cannot be compressed, and the compression of foam depends on the gas phase;

(3) the particle size and sphericity of the cuttings are constant, and the cuttings are evenly distributed in the flow;

(4) the rotating effect of the drill stem is not considered.

\subsection{Cuttings transport models}

Researchers reported from their experimental results that the cuttings bed in annuli is unstable under a certain range of well deviation. Martin et al. (1987), Li and Walker (1999) and Gao and Young (1995) reported that most unstable and difficult region for cuttings transport in deviated well was in the range of $30^{\circ}-60^{\circ}$ from vertical. The three sections with their angles from vertical were divided according to Cho et al. (2000a,b).

Based on the basic equation (Ozbayoglu et al., 2002, 2003; Avila et al., 2004; Mirhaj et al., 2007; Taghipour 

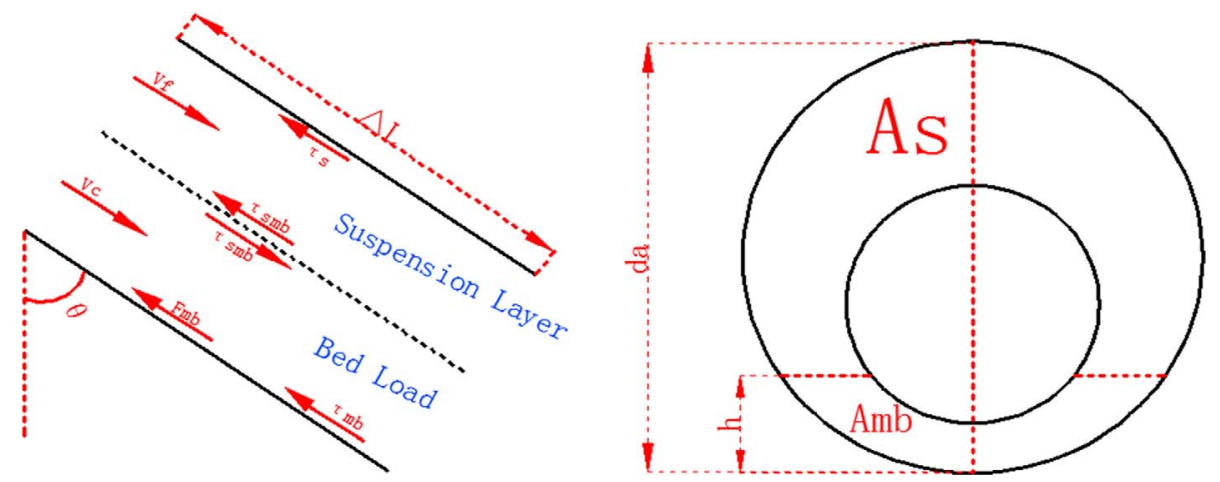

Fig. 1. Double layer transport models of cuttings transport in the transitional section.

et al., 2014; Cayeux et al., 2016), and considering the above basic assumed conditions, the cuttings transport models for various hole sections are obtained based on the mass and momentum conservation.

(1) Vertical/near vertical sections $\left(<30^{\circ}\right)$

$$
F_{\mathrm{B}}+F_{\mathrm{D}} \cos \theta+F_{\mathrm{L}}-\mathrm{G}>0
$$

(2) Transitional section $\left(30^{\circ}-60^{\circ}\right)$, as shown in Figure 1:

$$
v_{\mathrm{f}} A_{f} C_{f}+v_{c} A_{c} C_{c}-v_{c} A_{b} C_{b}=v_{t} A_{a}
$$

Suspension layer:

$$
\Delta P A_{s}=\tau_{s} S_{s} \Delta L+\tau_{s m b} S_{s m b} \Delta L+\rho_{s} g A_{s} \Delta L \cos \theta
$$

Bed load:

$$
\begin{aligned}
\Delta P A_{m b}+\tau_{s m b} S_{s m b} \Delta L= & \tau_{m b} S_{m b} \Delta L+\rho_{m b} g A_{m b} \Delta L \cos \theta \\
& +F_{m b} \Delta L
\end{aligned}
$$

(3) Inclined/horizontal sections $\left(>60^{\circ}\right)$, as shown in Figure 2:

$v_{s} A_{s} C_{s}+v_{m b} A_{m b} C_{m b}+v_{s b} A_{s b} C_{s b}-v_{v} A_{m b} C_{m b}=v_{t} A_{a}$

Suspension layer:

$$
\Delta P A_{s}=\tau_{s} S_{s} \Delta L+\tau_{s m b}^{\prime} S_{s m b}^{\prime} \Delta L+\rho_{s} g A_{s} \cos \theta \Delta L
$$

Dynamic cuttings bed:

$$
\begin{aligned}
\Delta P A_{m b}+ & \tau_{s m b}^{\prime} S_{s m b}^{\prime} \Delta L=\tau_{m b s b} S_{m b s b} \Delta L+\rho_{m b} g A_{m b} \\
& \times \cos \theta \Delta L+F_{m b} \Delta L+F_{m b s b} \Delta L
\end{aligned}
$$

The detailed derivations and the various parameters are given in the two articles of Cho et al. (2000) and given by Ozbayoglu et al. $(2002,2003)$. The model is compared with the model established by Ozbayoglu et al. (2003) about cuttings transport with foam. Its scope is more extensive, and it established corresponding solving equations for different parts of the well. In addition, the three-layer theory applied to the foam drilling cuttings transport in the study. The model improved the cuttings transport of the three hydraulic model studied by Nguyen and Rahman (1998). The model is simple in form, which greatly simplifies the work done by computer to find a solution, and by subsection modeling its applicability is stronger.

\section{Solution and verification of the models}

\subsection{Solution of the models}

The vertical/near-vertical sections can be obtained directly from the model. The transitional section and the inclined/ horizontal sections can be obtained by deforming the momentum conservation equation.

(1) Transitional section

$$
\frac{A_{s}}{A_{m b}}=\frac{\tau_{s} S_{s}+\tau_{s m b} S_{s m b}+\rho_{s} g A_{s} \cos \theta}{\tau_{m b} S_{m b}+\rho_{m b} g A_{m b} \cos \theta+F_{m b}-\tau_{s m b} S_{s m b}}
$$

(2) Inclined/horizontal sections

$$
\frac{A_{s}}{A_{m b}}=\frac{\tau_{s} S_{s}+\tau_{s m b} S_{s m b}+\rho_{s} g A_{s} \cos \theta}{\tau_{m b s b} S_{m b s b}+\rho_{m b} g A_{m b} \cos \theta+F_{m b}+F_{m b s b}-\tau_{s m b} S_{s m b}} .
$$

By calculating the proportion of the cuttings bed area to the total area of the wellbore to characterize the dimensionless thickness of the cuttings bed, we can more clearly analyze the relationship between the factors that affect the cuttings bed thickness. Thereby, we can determine reasonable drilling parameters to reduce the thickness of the bed of cuttings, realize drilling cost savings, and reduce drilling accidents. The inverse method can be used for the iterative computation of the cuttings bed thickness. First, suppose the cuttings bed thickness is $h$. The values of the various corresponding parameters are obtained, which are then substituted into the control equation group for calculation. If equations (8) and (9) are satisfied, then the supposed cuttings bed thickness is the correct value. Otherwise, a new $h$ needs to be supposed and the calculation repeated.

\subsection{Verification of the models}

To validate the proposed cuttings transport models, the corresponding calculating process is programmed for annulus 

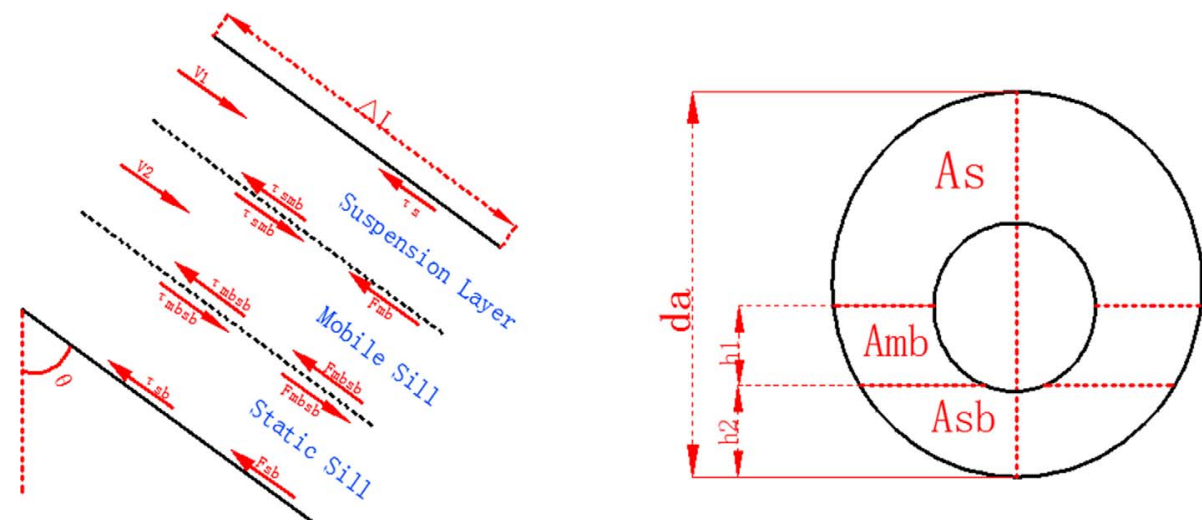

Fig. 2. Three layer transport models of cuttings transport in inclined/horizontal sections.

Table 1. Basic data for analysis.

\begin{tabular}{lclclc}
\hline Parameter & Data & Parameter & Data & Parameter & Data \\
\hline Vertical depth (KOP) & $1280 \mathrm{~m}$ & Wellbore diameter & $215.9 \mathrm{~mm}$ & Average particle size & $7 \mathrm{~mm}$ \\
Build-up section & $380 \mathrm{~m}$ & Drill pipe diameter & $127 \mathrm{~mm}$ & Cuttings sphericity & 0.8 \\
Build-up rate & $2.3^{\circ} / 10 \mathrm{~m}$ & Eccentricity & 0.6 & Drilling rate & $7.6 \mathrm{~m} / \mathrm{h}$ \\
Horizontal departure & $421 \mathrm{~m}$ & Cuttings density & $2.56 \mathrm{~g} / \mathrm{cm}^{3}$ & Bottom hole foam quality & $56 \%$ \\
Temperature gradient & $3^{\circ} \mathrm{C} / 100 \mathrm{~m}$ & Wellhead temperature & $23^{\circ} \mathrm{C}$ & Bottom hole bubble flow & $1.04 \mathrm{~m}^{3} / \mathrm{min}$ \\
\hline
\end{tabular}

cuttings transport rule analysis according to the basic data of one well (as shown in Tab. 1).

Figure 3 shows that the dimensionless cuttings bed average thickness at this horizontal interval is approximately $32 \%$, and it has exceeded the safety value (Han et al., 2012). Thus, the borehole cleaning is ineffective and it may cause a block of the drill stem trip. When the drill bit reaches the depth of $2020 \mathrm{~m}$, the trip is often blocked. This information shows that hole cleaning at the horizontal interval is inefficient and has resulted in a thick cuttings bed, which coincides with the predicted result of the models (Hall and Roberts, 1984; Fraser and Moore, 1987; FedererKovacs, 2005; Loureiro et al., 2010; Rooki et al., 2012; Gumati et al., 2013; Suradi et al., 2015).

\section{Influential factors of cuttings transport capacity of stable foam}

The cuttings transport capacity of stable foam is analyzed and evaluated by using the theoretical models.

\subsection{Influence of the inclination}

Figure 4 shows the distribution rules of the dimensionless cuttings bed thickness at various flow layers in the annulus, which change with hole inclination when the flow rate at the bottom hole is $1.04 \mathrm{~m}^{3} / \mathrm{min}$. With the decrease of the inclination $\theta$, the static thickness of the cuttings bed is gradually reduced, but the overall change is small. The dynamic

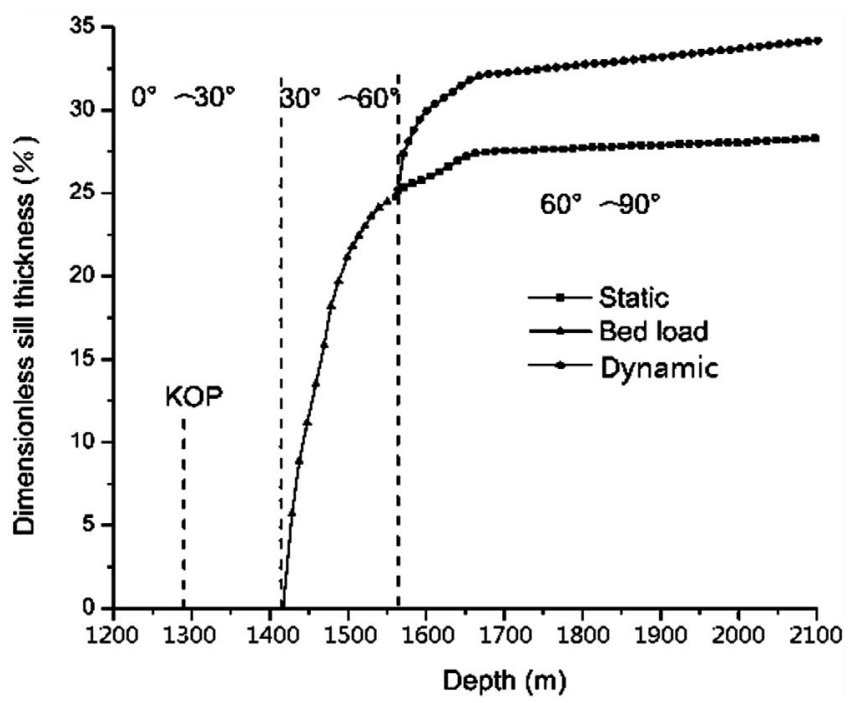

Fig. 3. Curves of the dimensionless cuttings bed thickness distributed with the well depth.

thickness increases slightly at first and then gradually decreases. Nevertheless, in general, the dimensionless thickness of the whole cuttings bed (static cuttings bed and dynamic cuttings bed) is gradually reduced. When the inclination $\theta$ is reduced to approximately $60^{\circ}$, the static cuttings bed and the dynamic cuttings bed disappear and are replaced by a glide lamella, which consists of cuttings 


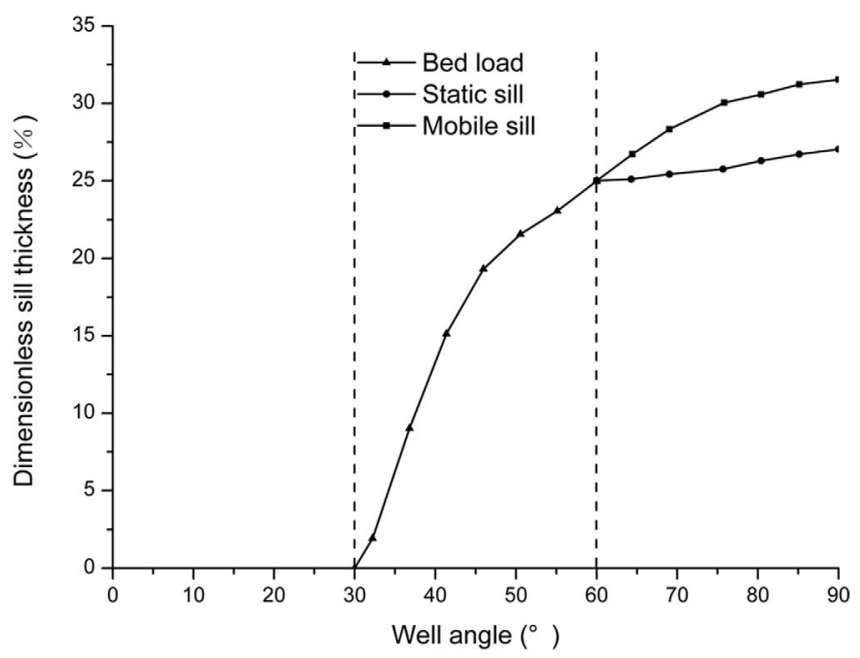

Fig. 4. Curves of the dimensionless cuttings bed thickness changes with the inclination.

grains. There are various forms of movement of this layer in the lower borehole. With the further decrease of the inclination $\theta$, the cuttings grains near the top surface of this layer will enter the annulus layer because of the drag force and the lifting force of the foam. This phenomenon will lead to the decrease of the cross-sectional area of this layer with the decrease of the inclination $\theta$. When the inclination is reduced to below $30^{\circ}$, the cuttings do not normally deposit in the borehole to form a cuttings bed. Given the small inclination at this time, the cuttings float on the foam fluid.

\subsection{Influence of the foam flow velocity}

As shown in Figure 5, with an increase of annulus velocity, the thickness of the dimensionless cuttings bed will be reduced gradually. When the thickness is increased from $0.6 \mathrm{~m} / \mathrm{s}$ to $0.9 \mathrm{~m} / \mathrm{s}$, the range of decrease is obviously larger than the $0.9 \mathrm{~m} / \mathrm{s}$ to $1.2 \mathrm{~m} / \mathrm{s}$ range. This finding shows that the increase of annulus velocity within a certain range will help improve the cuttings transport capacity of annulus foam. When the dimensionless cuttings bed thickness is at an inclination ranging between $30^{\circ}$ and $60^{\circ}$, the thickness of the whole cuttings bed will increase with the inclination. The thickness of the cuttings bed will remain unchanged or will slightly fluctuate within the $60^{\circ}-90^{\circ}$ range. With the increase of annular velocity, the thickness of the bed of cuttings shows a downward trend. When the annular velocity gradually increases from low flow rates, the cuttings bed thickness decreases rapidly. However, when the flow rate increases to a certain value, its impact on the cuttings bed thickness is reduced.

\subsection{Influence of the foam quality}

As shown in Figure 6, with the increase of the annulus flow velocity, the cuttings concentration speedily decreases and then basically remains unchanged. The cuttings concentration reduces with the increase of foam quality at the same annulus flow velocity, and it reaches a constant level at a

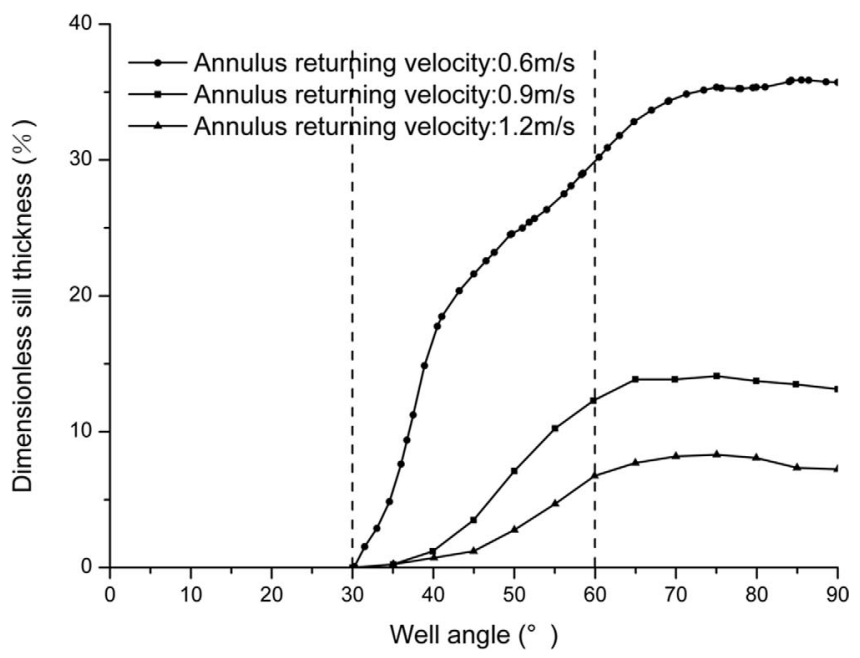

Fig. 5. Curves of the dimensionless cuttings bed thickness with different annulus foam flow velocities.

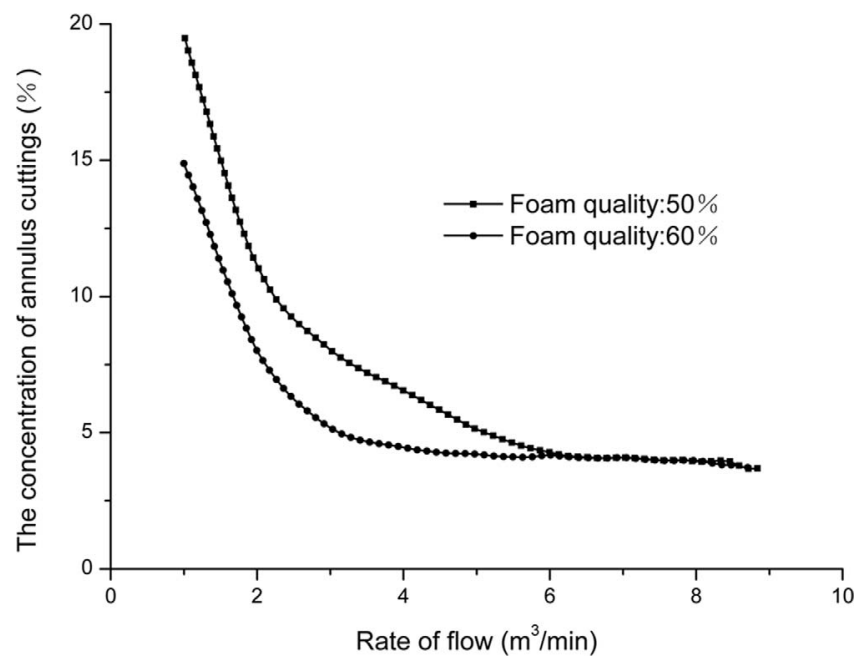

Fig. 6. Curves of the annulus cuttings concentration with the foam flow rate in different foam quality conditions.

lower annulus flow velocity with a higher foam quality. However, the cuttings concentration at the final stage is constant. Application of foam drilling process cannot guarantee the high quality of the foam: the foam should try to make the flow rate reach a critical speed with the increase of the quality of the foam when the foam cuttings bed thickness does not change with changes in the quality of the minimum flow.

\subsection{Influence of the drill stem eccentricity}

As shown in Figure 7, the thickness of the cuttings bed in the annulus increases with the gradual increase of the drill stem eccentricity. In addition, from the slope of each segment of the curve, we can see that the change of eccentricity has more influence on the cuttings bed thickness when the eccentricity is large, and it has less influence while small. 


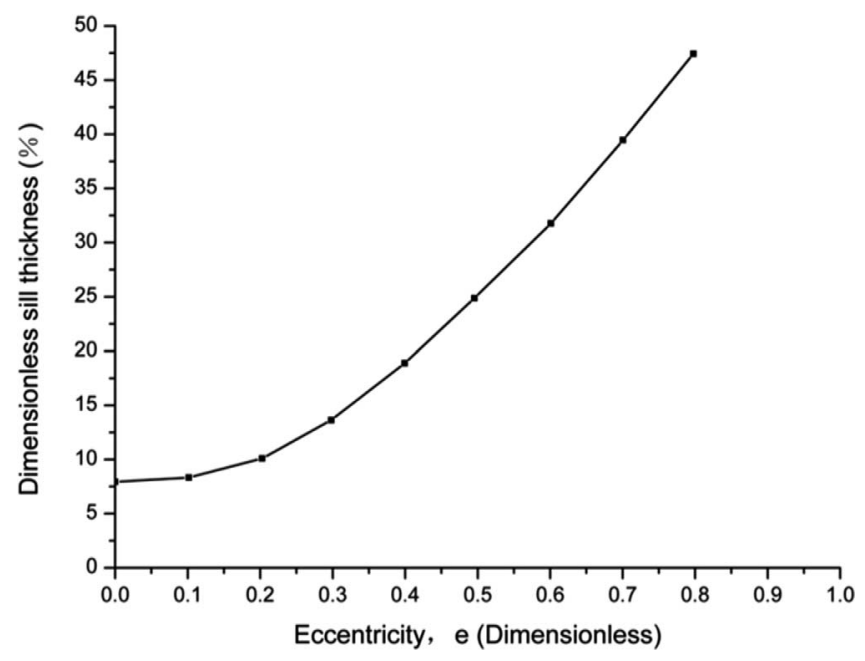

Fig. 7. Curve of the dimensionless cuttings bed thickness with the drill stem eccentricity.

Particularly when the eccentricity is reduced to 0.2 , the annulus cuttings bed thickness does not change too much for the continuous decrease of eccentricity. This finding is attributed to the fact that, with the decrease of eccentricity, the drill stem will not contact the cuttings bed beneath the annulus and the effect of eccentricity on the flow field will also be reduced. Thus, the continuous decrease of eccentricity will have little effect on the cuttings bed thickness. Therefore, the correction of eccentricity should be considered during the design of the drill stem structure to reduce the cuttings bed thickness effectively.

\section{Conclusion}

(1) When the inclination angle above $30^{\circ}$, the annulus cuttings bed thickness is reduced with the decrease of the inclination. When the inclination is reduced to below $30^{\circ}$, the cuttings do not normally deposit on the borehole to form a cuttings bed.

(2) The annulus dimensionless cuttings bed thickness is gradually reduced with the increase of annulus velocity. However, the improved effect of foam velocity on cuttings cleaning is significant only within a certain range of velocity.

(3) When the annulus flow velocity is increased, the cuttings concentrations will be reduced first at a fast speed, and then they will remain unchanged.

(4) During drilling, the drill stem eccentricity will have a significant influence on the annulus cuttings bed thickness. Thus, during drilling, operators should try to ensure that the eccentricity of the drill stem is low to reduce the thickness of the cuttings bed.

(5) When the flow rate of the foam reaches critical velocity, it can be appropriate to reduce the foam quality requirements in order to save the cost of drilling.
Acknowledgments. This work was supported by the Natural Science Foundation of China (NSFC) (No. 51274168) and the National Key Basic Research and Development Program (973 Program) (No. 2013CB228003).

\section{References}

Avila R., Pereira E., Miska S., Takach N., Saasen A. (2004) Correlations and analysis of cuttings transport with aerated fluids in deviated wells, IADC/SPE Drilling Conference, 2-4 March, Dallas, Texas, USA, Society of Petroleum Engineers.

Cayeux E., Leulseged A., Kluge R., Haga J. (2016) Use of a transient cuttings transport model in the planning, monitoring and post analysis of complex drilling operations in the North Sea, IADC/SPE Drilling Conference and Exhibition, 1-3 March, Fort Worth, Texas, USA, Society of Petroleum Engineers.

Cho H., Shah S.N., Osisanya S.O. (2000a) A three-layer modeling for cuttings transport with coiled tubing horizontal drilling, The 2000 SPE Annual Technical Conference and Exhibition, October 1-4, Dallas, Texas, USA, Society of Petroleum Engineers.

Cho H., Shah S.N., Osisanya S.O. (2000b) A three-segment hydraulic model for cuttings transport in horizontal and deviated wells, SPE/CIM International Conference on Horizontal Well Technology, 6-8 November, Calgary, Alberta, Canada, Society of Petroleum Engineers.

Federer-Kovacs G. (2005) Improve efficiency of cutting transport with foam drilling, 5th International Conference of PhD Students, University of Miskolc, Hungary, pp. 14-20.

Ford J. (1993) Development of mathematical models describing drilled cuttings transport in deviated wells, Paper 93-1102 presented at the 1993 CADE/CAODC Spring Drilling Conference, Calgary.

Ford J.T., Peden J.M., Oyenyin M.B., Gao E., Zarrough R. (1990) Experimental investigation of drilled cuttings transport in inclined boreholes, SPE 20421, 65th Annual Technology Meeting of SPE, New Orleans.

Fraser I.M., Moore R.H. (1987) Guidelines for stable foam drilling through permafrost, SPE/IADC Drilling Conference, New Orleans.

Gao E., Young A.C. (1995) Hole cleaning in extended reach wells, SPE Paper 29425 presented at the 1995 IADC/SPE Drilling Conference, Amsterdam, The Netherlands.

Gavignet A.A., Sobey I.J. (1986) A model for the transport of cuttings in highly deviated wells, SPE Annual Technical Conference and Exhibition, New Orleans, LA, USA.

Gumati A., Takahashi H., Giwelli A.A. (2013) Effect of drill pipe rotation on cuttings transport during horizontal foam drilling, J. Jpn Pet. Inst. 56, 4, 230-235.

Hagar J.M., Tian S., Adewumi M.A., Watson R.W. (1995) An experimental study of particle transport in a deviated wellbore, J. Can. Petrol. Technol. 34, 2, 51-54.

Hall D.L., Roberts R.D. (1984) Offshore drilling with preformed stable foam, SPE California Regional Meeting, Long Beach, $C A, U S A$, Society of Petroleum Engineers.

Han S.M., Kim J.H., Hwang Y.K., Woo N.S., Kim Y.J. (2012) An experimental study of cuttings transport in directional slim hole drilling, J. Ocean Eng. Technol. 26, 2, 20-25.

Kamp A.M., Rivero M. (1999) Layer modeling for cuttings transport in highly inclined wellbores, Latin American and 
Caribbean Petroleum Engineering Conference, Caracas, Venezuela, Society of Petroleum Engineers.

Kelessidis V.C., Bandelis G.E. (2003) Flow patterns and minimum suspension velocity for efficient cuttings transport in horizontal and deviated wells in coiled-tubing drilling, SPE/ICoTA Coiled Tubing Conference and Exhibition, Houston, Texas, USA, Society of Petroleum Engineers.

Kelessidis V.C., Bandelis G.E. (2004) Flow pattern and minimum suspension velocity for efficient cuttings transport in horizontal and deviated well in coiled-tubing drilling, SPE Drill. Completion 19, 4, 213-227.

Larsen T.I., Pilehvari A.A., Azar J.J. (1997) Development of a new cuttings transport model for high-angle wellbores including horizontal wells, SPE Drill. Completion 12, 02, 129-135.

Li J., Walker S. (1999) Sensitivity analysis of hole cleaning parameters in directional wells, SPE Paper 54498 presented at the 1999 SPE/ICoTA Roundtable, Houston, Texas, USA.

Loureiro B.V., de Paula R.S., Serafim M.B., Martins A.L. (2010) Experimental evaluation of the effect of drill string rotation in the suspension of a cuttings bed, Latin American and Caribbean Petroleum Engineering Conference, Lima, Peru, Society of Petroleum Engineers.

Luo Y., Bern F.A. (1992) Flow-rate predictions for cleaning deviated wells, Paper IADC/SPE 23884 presented at the 1992 IADC/SPE Drilling Conference, New Orleans.

Martin M., George C., Bison P., Konirsch O. (1987) Transport of cuttings in directional wells, SPE Paper 16083 presented at the 1987 IADC/SPE Drilling Conference, New Orleans, LA, USA.

Masuda Y., Naganawa S., Doan Q., Yonezawa T., Kobayashi A., Kamp A. (2000) Experimental study to determine critical flow rate of cuttings transport during underbalanced drilling, $I A D C / S P E$ 62737, to be presented at the $2000 I A D C / S P E$ Asia Pacific Drilling Technology held in Kuala Lumpur, Malaysia.

Mirhaj S.A., Shadizadeh R., Fazaeli-zadeh M. (2007) Cuttings removal simulation for deviated and horizontal wellbores, $S P E$ Middle East Oil and Gas Show and Conference, Bahrain, Kingdom of Bahrain.

Nguyen D., Rahman S.S. (1998) A three-layer hydraulic program for effective cuttings transport and hole cleaning in highly deviated and horizontal wells, SPE Drill. Completion 13, 03, 182-189.

Ozbayoglu E.M., Miska S.Z., Reed T., Takach N. (2003) Cuttings transport with foam in horizontal \& highly-inclined wellbores, SPE/IADC Drilling Conference, Amsterdam, Society of Petroleum Engineers.

Ozbayoglu M.E., Kuru E., Miska S., Takach N. (2002) A comparative study of hydraulic models for foam drilling, $J$. Can. Petrol. Technol. 41, 06, 52-61.

Piroozian A., Ismail I., Yaacob Z., Babakhani P., Ismail A.S.I. (2012) Impact of drilling fluid viscosity, velocity and hole inclination on cuttings transport in horizontal and highly deviated wells, J. Petrol. Explor. Prod. Technol. 2, 3, 149156.

Rooki R., Ardejani F.D., Moradzadeh A., Norouzi M. (2012) Cuttings transport modeling in foam drilling using computational fluid dynamics (CFD), World Appl. Sci. J. 17, 4, 524531.

Rooki R., Ardejani F.D., Moradzadeh A., Norouzi M. (2014) Simulation of cuttings transport with foam in deviated wellbores using computational fluid dynamics, J. Pet. Explor. Prod. Technol. 4, 3, 263-273.

Sample K.J., Bourgoyne A.T. (1977) An experimental evaluation of correlations. Used for predicting cuttings slip velocity, Paper SPE 6645 presented at the 1977 SPE Annual Technical Conference and Exhibition, Denver, CO, USA

Sample K.J., Bourgoyne A.T. (1978) Development of improved laboratory and field procedures for determining the carrying capacity of drilling fluids, Paper SPE 7497 presented at the 1978 SPE Annual Technical Conference and Exhibition, Houston, TX, USA.

Suradi S.R., Mamat N.S., Jaafar M.Z., Sulaiman W.R.W., Ismail A.R. (2015) Study of cuttings transport using stable foam based mud in inclined wellbore, J. Appl. Sci. 15, 5, 808.

Taghipour A., Lund B., Ytrehus J.D., Skalle P., Saasen A., et al. (2014) Experimental study of hydraulics and cuttings transport in circular and noncircular wellbores, J. Energy Resour. Technol. 136, 2, 022904.

Tomren P.H., Iyoho A.W., Azar J.J. (1983) An experimental study of cuttings transport in directional wells, 58th SPE Annual Technical Conference and Exhibition, SPE 12123. 